\title{
Motivational structure of female and male dancers of different dance disciplines
}

\author{
Petra Zaletel* and Tanja Kajtna \\ Faculty of Sport, University of Ljubljana, Ljubljana, Slovenia
}

Copyright: (C) 2020 P. Zaletel and T. Kajtna. This is an open access article licensed under the Creative Commons Attribution License (https://creativecommons.org/licenses/by/4.0/).

\begin{abstract}
Background: Success in the sport of dance is determined not only by physical and aesthetics factors but also with psychological preparation, where motivation is one of the most important dimensions. In motivated dance performances, athletes try harder than usual, put more attention on their sport and everything connected with it, choose to have longer trainings and compete better. Objective: The aim of our study was to explore the motivation structure of female and male dancers from four different dance disciplines (Latin American and ballroom, acrobatic rock'n'roll, modern-jazz, ballet) to determine the role of efficiency-oriented and competitive motivation on practice and results. Methods: A questionnaire of competitive motives was used to determine the motivational scale of motives of individual subjects. A total of 110 top female and male dancers were compared by gender and dance discipline with a two-way analysis of variance according to their motivation. Factor analysis was used to determine the latent factors of their motivation so as to more precisely explain what drives a dancer, since a large number of explicit variables is more clearly presented through its latent structure. Results: Females pay more attention to the motives of self-control, emotional relaxation, self-awareness, and to socially-oriented motives. Male dancers have significantly less negative competitive motivation. Sport dancers (Latin American and ballroom, rock'n'roll) have a bigger need for self-respect. Social needs are the most important for the Latin American and ballroom dancers, the motive for self-actualization is a priority of both modern-jazz dancers and sport dancers, the possibilities of self-control are very important for modern-jazz and ballet dancers. Conclusions: We found that male dancers tend to be dominating and leading with a strong power motive, while female dancers are more focused on motives like emotional relaxation, self-control and social understanding.
\end{abstract}

Keywords: ballroom, Latin American, self-respect, top-level athletes, latent structure

\section{Introduction}

Sport dancing in Slovenia has a long-standing tradition. Dancers have many great international successes in sport dancing competitions. Bigger national and international competitions demand more precision, systematic and professional work from young dancers and a more holistic, interdisciplinary approach to this sport discipline. Thus an interdisciplinary approach including kinesiological, psychological and sociological points of view can be desirable for improving results in the sport.

Sport dancers have to be physically well prepared to achieve the status of a top dancer, achieve harmony in movement, precision, synchronisation with music

\footnotetext{
* Address for correspondence: Petra Zaletel, Department of Dance, Aerobics and Fitness, Faculty of Sport, University of Ljubljana, Gortanova 22, 1000 Ljubljana, Slovenia. E-mail: petra.zaletel@fsp.uni-lj.si
}

etc. Artistic or, even better, aesthetic preparation is one step above physical preparation yet all three are merging together.

The positive motivation for competition is far more important for success than negative motivation. The concept of efficiency-oriented motivation is related to competing and the need for victory. Many studies claim that competitiveness is more emphasized in male athletes than in female athletes (Gill, Dzewaltowski, \& Deeter, 1988; Nicholls, 1989). Encouraging others to act, think and behave in a certain way is the responsibility of many people (e.g. coaches) and motivating others can be very challenging (Mallet, Kawabata, Newcombe, Otero-Forero, \& Jackson, 2007). People with higher levels of self-determined motivation are more efficient, use positive coping strategies in stressful situations (Amiot, Gaudreau, \& Blanchard, 2004), persist longer and invest more effort in activities (Pelletier et al., 1995). In sport actions of achievement behaviour 
athletes try harder than usual, put more attention on their sport and everything connected with it, choose to have longer training and compete better and stay in sport or finish training (Adie, Duda, \& Ntoumanis, 2008; Tušak, 1997).

Gill, Gross, and Huddleston (1983) found eight general factors as the main motives for being involved in sport: the need for achievement, group (team) spirit, recreational motives, to relieve tension, the improvement of one's abilities, friendship, entertainment and several other motives. Similar motives were found in other researches: sociability, recognition, the need for achievement and self-confirmation (Zaletel, Tušak, \& Zagorc, 2006).

The main motives for women participating in dance classes are first to make new friends and connections, then positive effects on motor abilities and reducing one's body fat (Roy, 1981). Many authors are, besides physiological parameters, establishing some psychological ones: changes in self-concept, self-awareness, lower anxiety and depressive moods, greater creativity, self-confidence, motivation, relaxation, better health and a bigger quantity of energy (Gurley, Neuringer, \& Massee, 1984; Pappalardo, 1980; Vilhjalmsson \& Thorlindsson, 1992).

The viewpoints and motives of folk, modern and sport dancers of both genders are satisfaction, enjoyment in movement in music and appreciating the beauty and harmony of movement. The need to improve physical abilities and creativity are the motives of modern dancers; folk dancers have a need for social connections; also one's family, parents' dance and music education have a big influence on a young dancer's decision to participate in sport dance (Zaletel et al., 2006). A comparison of 500 female and male sport dancers (Ipavec, Zaletel, \& Zagorc, 1998) showed similarities between the motives of dancers of different dance disciplines (both genders). The most important motives for dance were a need for rhythmic movement, the need to spend energy, the need to express feelings, the need for imitation and play, social needs and the need for aesthetics.

Some authors established that athletes (in comparison with non-athletes) have a stronger and more dominant ego, masculinity and practicality (Maslow, 1970; Tušak \& Tušak, 1997). Athletes can easily adjust and have more confidence in themselves. On the other hand, they often feel like they are depending on a group in comparison with non-athletes. Athletes have greater self-confidence and a more positive self-concept than non-athletes (Tušak \& Tušak, 1997). Hip-hop dancers' (hip hop is part of modern competitive dances, like jazz and modern dance) perceptions of task-involving climates positively predict satisfaction of the needs for autonomy, competence, and relatedness (Quested \& Duda, 2009). Vivi and Juneman (2015) found that the hedonistic perspective is important for hip-hop dancers and it is understandable that perceptions of ego-involving climate significantly and negatively predicted relatedness. Competence was found mediate the associations between dancers' perceptions of the taskinvolving features of the dance climate end their experiences of positive and negative affective states (Quested \& Duda, 2010).

The main purpose of this paper was to observe the motivation structure of female and male dancers from four different disciplines (Latin American and ballroom, acrobatic rock'n'roll, modern-jazz, ballet) to determine the role of efficiency-oriented and competitive motivation on their training and results. Another aim was also to determine the latent factors of their motivation so as to more precisely explain what drives a dancer, since a large number of explicit variables is more clearly presented through its latent structure (Fajgelj, Bala, \& Katić, 2010; Sporiš et al., 2012).

\section{Methods}

\section{Participants}

Recruitment of the participants was performed through representatives of the Dance Association of Slovenia and the coaches of national teams of individual dance genres. All distributed questionnaires were completed by the dancers on-site and returned immediately to the researcher. The four-group sample consisted of 110 individuals: 29 Latin American and ballroom dancers (14 females, 15 males; age $18.6 \pm 5.2$ years), 31 acrobatic rock-and-roll dancers (15 females, 16 males; age $19.6 \pm 6.2$ years), 25 modern-jazz dancers ( 15 females, 10 males; age $20.5 \pm 4.3$ years) and 25 ballet dancers ( 15 females, 10 males; age $18.9 \pm 2.8$ years). All participants were 15 to 24 years old (age $19.5 \pm 4.6$ years). In 2017 all the top-level athletes were members of respective (junior and/or senior) national teams.

\footnotetext{
Materials

A questionnaire of competitive motives was used to determine the motivational scale of motives of individual subjects (Tušak, 1997). It comprises 95 statements/ items which participants evaluate according to whether they are beneficial or harmful to them with a YES/NO or on a scale from 0 to $4(0=$ very harmful, unfavourable for me, 1 = little harmful to me, 2 = neither beneficial nor harmful to me, $3=$ somewhat useful to me, 4 = very useful for me, harmless). The questionnaire is composed so that certain statements are summed up, with the result being a maximum of 20 points. The
} 
total sum of all the scales gives us the overall score for competitive motivation. The intention of the evaluation scale is to identify dancers' motivational characteristics and hence consists of 19 categories (items): (1) FAMILY - sport can often be a substitute for a family or an athlete can make his position or relations in sport similar to those in a family; (2) EMOTIONAL RELAXATION - gaining emotional satisfaction through sport activity; (3) HETSEXUALITY - possibilities to meet and make contact with people of the opposite sex; (4) INTIMIDATION AND CONTROL from the athlete's environment (from the outside); (5) RECREATION AND HEALTH - concern for health and physical recreation through sport; (6) INDEPENDANCE - the athlete can plan training alone, they do not need advice, criticism, they can do other things by themselves; (7) clear and obvious BENEFITS; (8) SELF CONTROL - athletes' possibility to learn to control him/herself through participation in sport; (9) friendship and SOCIAL CONNECTIONS including the possibilities of gaining, keeping and building good interpersonal relationships; (10) RECOGNITION; (11) UNDERSTANDING the REASONS for training; (12) FEAR OF FAILURE; (13) SOCIAL APPROVAL of sport results; (14) STATUS in social contacts; (15) SELF-AWARENESS; (16) the need for (tendency towards) competition (NEED COMPETITION); (17) COMPETITIVE CONDITIONS; (18) SUCCESS and EFFECTIVENESS - to succeed, to achieve a certain social status, to be productive; (19) LIFESTYLE through involvement in sport. The test-retest of reliability was .93 for the whole scale and .76 for the reliability of subscale.

The Sport Attitudes Inventory (Tušak, 1997) measures three main motives for competing: (1) the power motive (POWER); (2) the motivation to avoid failure (FAILURE AVOIDANCE) and (3) the motivation to achieve success (ACHIEVING SUCCESS). It is composed of 40 statements/items which participants evaluate on a 1 (do not agree at all) to 5 (strongly agree) scale. The inventory is composed so that certain statements can be summed up, with the result being a maximum of 100 . The test-retest of reliability was for power motive scale .75 , for positive motivation .69 and for negative motivation .71 .

\section{Procedures}

The questionnaires were administered to four separate groups of dancers. The results for all groups were collected anonymously. The data was processed using IBM SPSS Statistics (Version 23.0 for Windows; IBM, Armonk, NY). Kolmogorov-Smirnov test showed normal data distribution. Besides descriptive statistics methods, a two-way analysis of variance was used to determine the differences in motivation among female and male dancers (with regard to their gender and among groups with different dance disciplines). The differences between the different groups of dancers were checked by Tukey HSD post hoc test. Statistical significance was confirmed at the level of $5 \%$ probability of error $(p \leq .05)$.

The factor analysis (the principal components method, varimax rotation) served as the means for discovering whether the selected population of top dancers differs significantly in their latent factors of motivation as regards their gender and dance discipline. Factor analysis is designed with the objective to identify certain unobservable factors from the observed variables, that is why we reduced the large number of motivational variables to four latent factors, which represented combined motives of dancers.

The research was approved by the Ethical Committee of the Faculty of Sport, University of Ljubljana, participants or their legal representatives signed an informed consent form to participate in the research.

\section{Results}

The first part of our results deals with gender differences and the differences between dancers of different dance disciplines. The second part concerns a factor analysis of the motivational categories including the differences in latent factors of the motivational structure as regards the dancers' gender and involvement in each discipline.

The average values of motivational categories (Table 1) show the main motives for dancers' activity: success and efficiency, self-control, the need for recreation and good health and the need for emotional relaxation. Their less important motives are heterosexuality, the need to avoid failure (negatively oriented motivation) and to gain status through involvement in dance.

The comparison of the motivation of female and male dancers (Table 1) proves that female dancers pay more attention to the motives of self-control, emotional relaxation, self-awareness, understanding the reasons for training and to those motives that help develop a lifestyle through their dance involvement. Also, more important for the female dancers are socially oriented motives: social approval, family influence, the need for clear and obvious benefits, the need for friendships and personal relations. Differences in achievement motivation between all male and female dancers prove, that male dancers have significantly less negative competitive motivation - their final goal is always success while the female dancers are more motivated to avoid failure (Table 1). 
Table 1

Values of motivational categories and differences between all male and female dancers

\begin{tabular}{|c|c|c|c|c|c|}
\hline Motivational category & $\begin{array}{l}\text { All dancers } \\
(N=110)\end{array}$ & $\begin{array}{c}\text { Males } \\
(n=49)\end{array}$ & $\begin{array}{l}\text { Females } \\
(n=61)\end{array}$ & $F$ & $p$ \\
\hline Family & 14.25 & 13.57 & 14.80 & 5.63 & .02 \\
\hline Emotional relaxation & 16.84 & 16.00 & 17.51 & 13.10 & $<.01$ \\
\hline Heterosexuality & 11.45 & 11.63 & 11.30 & 0.40 & .53 \\
\hline Intimidation and control & 14.01 & 14.10 & 13.93 & 0.13 & .72 \\
\hline Recreation and health & 17.88 & 17.69 & 18.03 & 0.95 & .33 \\
\hline Independence & 13.66 & 13.59 & 13.72 & 0.08 & .78 \\
\hline Benefits & 16.58 & 15.80 & 17.21 & 10.44 & $<.01$ \\
\hline Self-control & 17.87 & 17.18 & 18.43 & 9.86 & $<.01$ \\
\hline Social connections & 16.15 & 15.51 & 16.67 & 6.39 & .01 \\
\hline Recognition & 13.33 & 12.82 & 13.74 & 2.22 & .14 \\
\hline Understanding reasons & 16.92 & 16.47 & 17.28 & 5.42 & .02 \\
\hline Fear of failure & 12.13 & 12.49 & 11.84 & 1.21 & .27 \\
\hline Social approval & 15.35 & 14.61 & 15.93 & 8.33 & .01 \\
\hline Status & 12.52 & 11.94 & 12.98 & 3.61 & .06 \\
\hline Self-awareness & 15.15 & 14.59 & 15.61 & 4.62 & .03 \\
\hline Need for competition & 13.24 & 13.24 & 13.23 & 0.00 & .98 \\
\hline Competition conditions & 15.41 & 15.22 & 15.56 & 0.39 & .53 \\
\hline Success, effectiveness & 18.28 & 17.94 & 18.56 & 3.28 & .07 \\
\hline Lifestyle & 15.80 & 15.22 & 16.26 & 7.10 & .01 \\
\hline Power & 41.71 & 42.61 & 40.98 & 3.36 & .07 \\
\hline Failure avoidance & 33.25 & 30.80 & 35.23 & 11.96 & $<.001$ \\
\hline Achieving success & 68.06 & 67.22 & 68.74 & 1.36 & .25 \\
\hline
\end{tabular}

There are differences in almost every motivational variable between different groups of dancers regardless of gender (Table 2). Post-hoc analysis showed the power motive and positive motivation (the need to achieve success) is expressed in the group of Latin American and ballroom dancers and modern-jazz dancers of both genders. Ballet dancers have a greater fear of failure in comparison with the acrobatic rock'n'roll dancers.

By using factor analysis, we tried to extract a few latent factors to give us a better overview of the whole motivational structure of dancers and a smaller space in which we could again search for any similarities and differences between them. Four components explain $54 \%$ of the variance (see Table 3), where the first factor is the strongest and explains $17 \%$ of the total variance of the system. The variables which have the largest projections on the first factor are: the motive for social approval, the need for clear and obvious benefits, friendly and personal connections, the motive for success and productivity, the influence of family, competitive conditions and the need to compete. Needs for respect include self-esteem and respect for others and other ego needs (Maslow, 1970). This includes the pursuit of power, productivity, self-confidence, freedom, reputation and status, fame and power. A special feature of this factor is that the need for self-esteem is associated with the competitive situation or the performance of dancers, so we named the first factor the need to achieve self-respect through success in dance.

The second factor is also strong because it explains $16 \%$ of the total variance of the system. The highest projections on this factor involve items which refer to recognizing people of the opposite gender, items relating to social relations and achieving a certain status in society which approves of such behaviour. Maslow (1970) compared needs for being a member of something, love and other social needs, which includes giving and accepting and which are more dominant in Western society. Athletes are content to be part of a team where they can fulfil such needs; they are content to be noticed, to have a certain status. We named the second factor "social needs" (being a member of something, acceptance, friendship, affection). 
Table 2

Differences in motivational categories between different groups of dancers

\begin{tabular}{|c|c|c|c|c|c|c|}
\hline Motivational category & $\begin{array}{l}\text { Sport dance } \\
\quad(n=29)\end{array}$ & $\begin{array}{l}\text { Rock'n' roll } \\
\qquad(n=31)\end{array}$ & $\begin{array}{l}\text { Ballet } \\
(n=25)\end{array}$ & $\begin{array}{l}\text { Modern-jazz } \\
\quad(n=25)\end{array}$ & $F$ & $p$ \\
\hline Family & 15.17 & 14.29 & 13.60 & 13.80 & 2.12 & .10 \\
\hline Emotional relaxation & 17.76 & 15.74 & 16.48 & 17.48 & 5.22 & $<.01$ \\
\hline Heterosexuality & 12.69 & 10.58 & 10.44 & 12.08 & 4.41 & .01 \\
\hline Intimidation and control & 13.93 & 13.52 & 14.04 & 14.68 & 1.14 & .34 \\
\hline Recreation and health & 18.14 & 17.94 & 16.84 & 18.56 & 4.18 & .01 \\
\hline Independence & 15.97 & 12.00 & 12.44 & 14.28 & 16.80 & $<.01$ \\
\hline Benefits & 17.86 & 16.03 & 15.48 & 16.88 & 6.03 & $<.01$ \\
\hline Self-control & 18.45 & 16.77 & 17.80 & 18.64 & 4.59 & .01 \\
\hline Social connections & 16.66 & 15.87 & 15.64 & 16.44 & 1.15 & .33 \\
\hline Recognition & 16.00 & 12.48 & 11.44 & 13.16 & 10.52 & $<.01$ \\
\hline Understanding reasons & 18.03 & 15.26 & 16.68 & 17.92 & 14.79 & $<.01$ \\
\hline Fear of failure & 12.69 & 11.00 & 11.80 & 13.20 & 2.86 & .44 \\
\hline Social approval & 16.38 & 15.10 & 14.56 & 15.24 & 3.16 & .03 \\
\hline Status & 14.03 & 11.13 & 12.04 & 12.96 & 5.58 & $<.01$ \\
\hline Self-awareness & 16.45 & 13.61 & 14.60 & 16.12 & 8.34 & $<.01$ \\
\hline Need for competition & 15.07 & 12.97 & 11.00 & 13.68 & 9.62 & $<.01$ \\
\hline Competition conditions & 17.76 & 15.77 & 13.00 & 14.64 & 14.39 & $<.01$ \\
\hline Success, effectiveness & 19.28 & 18.23 & 17.48 & 18.00 & 5.25 & $<.01$ \\
\hline Lifestyle & 17.00 & 14.35 & 15.76 & 16.24 & 8.88 & $<.01$ \\
\hline Power & 44.07 & 40.87 & 38.88 & 42.84 & 6.30 & $<.01$ \\
\hline Failure avoidance & 31.38 & 29.58 & 38.24 & 35.00 & 8.23 & $<.01$ \\
\hline Achieving success & 71.59 & 66.94 & 64.88 & 68.56 & 4.94 & $<.01$ \\
\hline
\end{tabular}

Table 3

Factor analysis of motivational categories

\begin{tabular}{lcccccccc}
\hline & \multicolumn{3}{c}{ Initial Eigenvalues } & & \multicolumn{3}{c}{ Rotation sums of squared loadings } \\
\cline { 2 - 3 } \cline { 7 - 8 } Component & Total & \% of variance & Cumulative \% & & Total & \% of variance & Cumulative \% \\
\hline Factor 1 & 7.52 & 39.56 & 39.56 & & 3.21 & 16.90 & 16.90 \\
Factor 2 & 1.71 & 9.02 & 48.58 & & 3.00 & 15.82 & 32.72 \\
Factor 3 & 1.56 & 8.21 & 56.79 & & 2.66 & 14.02 & 46.74 \\
Factor 4 & 1.17 & 6.16 & 62.96 & & 1.44 & 7.56 & 54.30 \\
\hline
\end{tabular}

The third factor (14\%) is formed by self-actualization and self-realization motives such as self-confidence, understanding of reasons (for training), emotional relaxation, self-control, lifestyle, independence and autonomy, which are the highest in the hierarchy of all motives (Maslow, 1970). They refer to the realization of someone's potential and the full development of their capabilities. The satisfaction of these needs is often accompanied by peak experiences, a feeling of happiness, beauty, harmony and perfection.

The fourth factor is poor because it only explains 7\% of the total variance of the system and has projections with just two items: fear of failure and intimidation and control. The dominance of this factor is a negatively oriented motivation and expresses the need to avoid failure in competitions.

The analysis of differences shows that the latent factors of the motivational structure between female and male dancers appear in first and third factors (Table 4). Female dancers have a greater need to achieve self-respect and self-actualization through success in dance. Some similar factors were found by other researchers when constructing motivational questionnaires for dancers - Maraz, Király, Urbán, Griffiths, 
Table 4

Comparison in latent factors of motivation between male and female dancers

\begin{tabular}{|c|c|c|c|c|}
\hline \multirow[b]{2}{*}{ Factor } & \multicolumn{2}{|c|}{ Mean } & \multirow[b]{2}{*}{$F$} & \multirow[b]{2}{*}{$p$} \\
\hline & Males & Females & & \\
\hline 1 & -.20 & .16 & 4.85 & .03 \\
\hline 2 & .00 & .00 & 0.40 & .53 \\
\hline 3 & -.25 & .20 & 7.62 & .01 \\
\hline 4 & .14 & -.11 & 1.88 & .17 \\
\hline
\end{tabular}

Table 5

Comparison in latent factors of motivation between groups of different dance disciplines

\begin{tabular}{|c|c|c|c|c|c|c|}
\hline \multirow[b]{2}{*}{ Factor } & \multicolumn{4}{|c|}{ Mean } & \multirow[b]{2}{*}{$F$} & \multirow[b]{2}{*}{$p$} \\
\hline & Sport dance & Rock'n'roll & Ballet & Modern-jazz & & \\
\hline 1 & .34 & .23 & .50 & .19 & 6.04 & $<.01$ \\
\hline 2 & .51 & .33 & .24 & .00 & 5.48 & $<.01$ \\
\hline 3 & .33 & .66 & .00 & .43 & 12.12 & $<.01$ \\
\hline 4 & .11 & .33 & .00 & .30 & 2.31 & .08 \\
\hline
\end{tabular}

and Demetrovics (2015) found factors such as fitness, mood enhancement, intimacy, socialising, trance, mastery, self-confidence and escapism.

The differences in the latent factors between the groups of different dance disciplines (Table 5) reveal a greater need for self-respect in the group of sport dancers (Latin American and ballroom, rock'n'roll dancers), social needs are the most important for the Latin American and ballroom dancers, the motive for selfactualization is a priority of both modern-jazz dancers and sport dancers.

\section{Discussion}

Our interpretation mainly focuses on differences between the genders on one hand and differences between the dance discipline groups on the other. Similarly, as in other top athletes (Šifrar \& Kajtna, 2014), dancers evaluate highly the motives of success and achievement, recreation and health, self-control, the need for understanding the reasons for a different kind of training, and the need for emotional relaxation. The dancers strongly agreed with statements such as: "the feelings of emotional satisfaction and pleasant feelings to be present in a sports environment", "to be able and to have the option to forget everything during competition", "to achieve calmness and emotion control through sports, away from everyday stress". Freedom to express emotions is very important in dance as the dancer has to convince the audience and judges that they really can feel and "live" through dance. Dancers seem to be intrinsically motivated to participate in training, which is a finding similar to that of Thesleff (2014).

The greater values for the self-control of female dancers show their tendency towards perfection, an improvement in their performance, and that for them success is learning. The female dancers are more workoriented, while the male dancers are more ego-oriented: they compare themselves against each other, success only lies in winning and they strive to be the best. The female dancers are very socially oriented; they pay a lot of attention to friendship and other personal relationships and social approval (Šifrar \& Kajtna, 2014). Dance abilities and aesthetic movement give female dancers the opportunity to gain social attention and an impression of a self-confident personality.

The female dancers perceive self-awareness as being a more important motivation category than their male counterparts. We can connect this fact with the "flow state" (Csikszentmihaly, 1990), which frequently occurs in creative, sporting or other circumstances that demand total attention. It represents the experience of pleasure, interest and even ecstasy that derives from activities that perfectly match one's skills with performance demands. Flow provides a sense of discovery, a creative feeling of transporting a person into a new reality. It pushes a person to higher levels of performance and leads to previously undreamed-of states of consciousnesses. 
The flow state has been defined as an intrinsic reward for participation in an activity, as an optimal state that occurs when there is a balance between the perceived challenges of a situation and a person's skills or capabilities for action (Csikszentmihaly, 1990) and "as the centering of attention to a limited stimulus field” (Webster, Trevino, \& Ryan, 1993, p. 72). Flow is also characterized by a heightened sense of playfulness (Webster \& Martocchio, 1992), self-control (Ghani \& Deshpande, 1994), increased learning, and enhanced positive subjective experiences (Maslow, 1970).

Flow is a distinctive motivating process because it is not only signalled by a perception of the matching of skill and demand but also incorporates other inferred motivating processes such as hypnosis, play, self-actualization, and psychic energy (attention).

Female dancers have a greater negative competitive motivation - fear of losing, avoiding failure - than the male dancers. Probably their expectations of the social environment are higher (Šifrar \& Kajtna, 2014). The female dancers perceive their appropriateness in social relations much better than their male counterparts, equally well within a dancing pair - in relation to their dancing partner as within their narrow circle (coach, partner, family) and broader circle of people. The female dancers find it important that society recognizes them, approves of their behaviour and that they readily form contacts with their environment. These characteristics are extremely important for dancing performances at competitions as in the category of dance interpretation judges also assess audience communication, partner communication and the behavioural appropriateness of the dancing pair in general.

A female dancer's self-concept is strongly influenced by her convictions concerning other people's opinions (Zaletel et al., 2006), which is also one of the influences on athlete's experiences of positive or negative emotional states (Soyer, 2012). Social desirability has been found to be high in athletes' also in other studies (Bastug, 2011), and we can say that in dancers this is particularly important, since they are in a way judged also by their appearance, not only performance. The control of the social community in turn influences the assimilation of her social processes and cultural patterns and thus forms her concept of self. In addition, role expectations of the social environment influence the female dancers more than the male dancers since they tend to behave accordingly, and thus affirm their "ideal" self in the reality of their social relations. The female dancers create their identity with the forming of nuclear roles (sexual, being a good friend, being an athlete etc.).

The comparison of the groups of different dance disciplines (regardless of their gender) confirms the nature of the Latin American and ballroom dances and the nature of modern-jazz dance. These two groups are motivated by emotional relaxation and opportunities for communication with people of the opposite gender. In Latin American dance the female and male dancers are often in a situation where they are trying to passionately or gently seduce one another with their movements, gestures, mimics, sensibility and sexuality. Dancers are great aesthetes and their role on stage frequently seeks to be attractive to the public and the judges. While acrobatic rock'n'roll is more of a type of "sport" dance and success is grounded more on the dancers' complex motor abilities, the thrust of rock'n'roll dance lies more in a powerful performance and strength.

The possibility to take care of one's health through sport is also most important for the group of Latin American and modern-jazz dancers. For ballet dancers, for example, dance is more of an occupation rather than a competition, which is probably why they are not motivated by competitive aspects in the same way the other dancers are.

The most fearless are the rock'n'roll dancers because they have to deal with dangerous acrobatics. Any fear or mere thought on trying to avoid failure could result in a nasty fall and injury.

Sport dancers (Latin American and ballroom dance) are, of all the groups, most motivated by independence, social approval and recognition, and by understanding the reasons for a certain type of training. They have a need to explore, ask, feed their curiosity, and a need to think which is very important for success in dance as a creative kind of sport. The role of the trainer passing information on to such dancers and giving them many different training situations is crucial here.

The power motive and positive motivation for competition are higher in the group of sport dancers and modern-jazz dancers. A similar motivational structure as our modern jazz dancers was found also by Aujla and Farrer (2016), who studied independent dancers. They seem to have no problems with competitive anxiety and are motivated by the number and importance of competitions. They are very oriented towards achievement and nothing seems to stop them on their way to success.

The comparison of the female and male dancers in the latent structure of their motivation shows that the need for commitment, love and respect are more important for the females. The need for respect also involves self-respect, a tendency towards power, achievement, self-confidence, freedom, reputation and status. The female dancers achieve confidence and satisfaction when they acquire certain knowledge, develop certain abilities or successfully finish a certain task. The need 
for respect also combines with the competitive situation and their dance performance.

The sport of dance gives female dancers an opportunity to extend their potential and develop a well-rounded personality. Achieving self-actualization is often accompanied by peak experiences, sense of extraordinary happiness, beauty, harmony and perfection (Maslow, 1970). The female dancers try to be more perfect in their dance - more expressive, aesthetic and noticed than the male dancers; probably that is why they tend to have ecstatic feelings in dance - they really "feel" the meaning of the dance. Their internal world is bigger and richer.

Ego needs as part of respect needs are, when comparing dancers of the different dance disciplines (regardless of gender), more dominant in the group of sport dancers (Latin American and ballroom) and rock'n'roll dance. The competitive orientation of these dancers brings out their power, achievement, self-confidence, reputation and status tendencies. They are content if the team notices and accepts them so that they have a certain status within the group. The competitive nature of Latin American and ballroom dance is also noticed in the big numbers of couples competing in pre-rounds. So, dancers have to be special, spotted and interesting. In the wish to stand out from the crowd there is often a need for recognition and dominancy in "ordinary" (non-sport) life.

The tendency towards accomplishing "greater" personal potential and personal growth is more recognized in the groups of modern-jazz and sport dance. Modern dance leans towards creative freedom in movement; a definite and precise expression is required in the interpretation of each dance. The impression of independence, unforced decisions (improvisation in modern dance) rewards the perceptions of self-actualized people who have many pleasant and ecstatic experiences along with a sense of perfection via their dance.

Dancers are self-actualized types of personalities or "realizers of the self-consciousness" (Musek, 1988). They have satisfied all their biological and physiological needs, the need for security, for love and respect so they do not have to direct their behaviour at those motives anymore. Dancers are more occupied and fulfilled by motives of personal growth, affinities to realize "higher" personal potential, and tendencies for self-completion. The author suggests that these personalities can really enjoy their lives because they do not depend on everyday worries; they can considerably increase and expand their autonomy, independence, they have a broader perception of freedom (of themselves and of reality) and they are also more capable of achieving triumphs in reality.
Dancers probably differ from others in their awareness and experience. Considering a dancer's expression, which is necessary to create an artistic impression, their internal world is complete, wider and more completely filled.

In the direction and selection of female and male dancers and choosing a proper dance discipline, parents, trainers and dance teachers must be very careful and distinguish which motives are driving an individual dancer to perform. Are they more competitive in nature or socially oriented or are they connected with the need for personal growth? On one hand, people who decide to take up dance sport have a specific personality and value system but, on the other hand, dance itself is also a huge stimulus for making, building and influencing one's psychological profile. But since dancing can be a highly motivating activity also for PE classes (Freitas da Rosa, Martins Reis, de Carvalho Souza Vieira, Folle, \& Coutinho de Azevedo Guimarães, 2018), we can see that the results of our study can be used also as a push for PE teachers to include dancing even more frequently into their work, both for boys and girls.

\section{Conclusions}

Motivation is essential when deciding on a specific dance discipline. Female sport dancers are often expected to be easy to work with and willing to devote themselves to top-level achievements. Female dancers are probably well aware of the expectations of their social environment and try to take on various roles, playing them out to perfection in accordance with their abilities, only to be often contradicted by their own "private" and "ideal" egos. That is why it is with them that it is often more difficult than with their partners to understand their nature, their various responses to similar situations (their reactions) as well as their behaviour - especially as they tend to transmit their vocational, professional behaviour into their private relationships (Zaletel et al., 2006). The research confirms the fact that the archetype of a woman's personality embraces an "eternity dancer" while the male personality contains a tendency, an attraction to the dominating, leading, "macho dancer" type. Male dancers have a stronger power motive and typical masculine characteristics which are crucial for success in sport.

\section{Conflict of interest}

There were no conflicts of interest. 


\section{References}

Adie, J. W., Duda, J. L., \& Ntoumanis, N. (2008). Autonomy support, basic need satisfaction and the optimal functioning of adult male and female sport participants: A test of basic needs theory. Motivation and Emotion, 32, 189-199.

Amiot, C. E., Gaudreau, P., \& Blanchard, C. M. (2004). Self-determination, coping, and goal attainment in sport. Journal of Sport and Exercise Psychology, 26, 396-411.

Aujla, I., \& Farrer, R. (2016). Independent dancers: Roles, motivation and success - Research report. Luton, United Kingdom: University of Bedfordshire.

Bastug, G. (2011). The study of athletes' body perception and gender role. Collegium Antropologicum, 35, 1037-1043.

Csikszentmihaly, M. (1990). Flow: The psychology of optimal experience. New York, NY: Harper \& Row.

Fajgelj, S., Bala, G., \& Katić, R. (2010). Latent structure of Raven's Colored Progressive Matrices. Collegium Antropologicum, 34, 1015-1026.

Freitas da Rosa, A., Martins Reis, N., de Carvalho Souza Vieira, M., Folle, A., \& Coutinho de Azevedo Guimarães, A. (2018). The practice of dance as extracurricular activity is related to higher motivation and physical activity level in students. Motricidade, 14(2-3), 3-10.

Ghani, J. A., \& Deshpande, S. P. (1994). Task characteristics and the experience of optimal flow in human-computer interaction. Journal of Psychology, 128, 381-391.

Gill, D. L., Dzewaltowski, D. A., \& Deeter, T. E. (1988). The relationship of competitiveness and achievement orientation to participation in sport and nonsport activities. Journal of Sport \& Exercise Psychology, 10, 139-150.

Gill, D. L., Gross, J. B., \&. Huddleston, S. (1983). Participation motivation in youth sports. International Journal of Sport Psychology, 14, 1-14.

Gurley, V., Neuringer, A., \& Massee, J. (1984). Dance and sport compared: Effects on psychological well-being. Journal of Sports Medicine, 24, 58-68.

Ipavec, N., Zaletel, P., \& Zagorc, M. (1998). Motivation structure of dancers. In M. Pavlovič (Ed.), Šport mladih: III. Mednarodni simpozij (pp. 399-404). Ljubljana, Slovenia: University of Ljubljana.

Mallett, C., Kawabata, M., Newcombe, P., Otero-Forero, A., \& Jackson, S. (2007). Sport motivational scale-6 (SMS-6): A revised six-factor sport motivation scale. Psychology of Sport and Exercise, 8, 600-614.

Maraz, A., Király, O., Urbán, R., Griffiths, M. D., \& Demetrovics, Z. (2015). Why do you dance? Development of the Dance Motivation Inventory (DMI). PLOS ONE, 10, e012286.

Maslow, A. H. (1970). Motivation and personality (2nd ed.). New York, NY: Harper \& Row.

Musek, J. (1988). Teorije osebnosti [Theories of personality]. Ljubljana, Slovenia: University of Ljubljana.

Nicholls, J. G. (1989). The competitive ethos and democratic education. Cambridge, MA: Harvard University Press.
Pappalardo, M. D. (1980). The effects of discotheque dancing on selected physiological and psychological parameters of college students. Dissussion Abstracts International, 40, 12.

Pelletier, L. G., Fortier, M. S., Vallerand, R. J., Tuson, K. M., Briere, N. M., \& Blais, M. R. (1995). Toward a new measure of intrinsic motivation, extrinsic motivation, and motivation in sports: The sport motivation scale (SMS). Journal of Sport and Exercise Psychology, 17, 35-53.

Quested, E., \& Duda, J. L. (2009). Perceptions of the motivational climate, need satisfaction, and indices of well- and ill-being among hip hop dancers. Journal of Dance Medicine and Science, 13, 10-19.

Quested, E., \& Duda, J. L. (2010). Exploring the social-environmental determinants of well- and ill-being in dancers: A test of basic needs theory. Journal of Sport \& Exercise Psychology, 32, 39-60.

Roy, S. (1981). Happy feet: Dance programs market fitness, fun and friendship. Sport Style 3, 14, 12-13.

Šifrar, T., \& Kajtna, T. (2014). Osebnostne dimenzije, čustvena inteligentnost in socialne spretnosti plesalk in plesalcev $v$ športnem plesu [Personality dimensions, emotional intelligence and social skills of dancers in sport dance]. Ljubljana, Slovenia: University of Ljubljana.

Soyer, F. (2012). The effects of positive and negative emotionality on the satisfaction of sport: A research on elite athletes. Collegium Antropologicum. 36, 937-943.

Sporiš, G., Šamija, K., Vlahović, T., Milanović, Z., Barišić, V., Bonacin, D., \& Talović, M. (2012). The latent structure of soccer in the phases of attack and defense. Collegium Antropologicum, 36, 593-603.

Thesleff, P. (2014). Participation in dance training in Finland - A study of motives and behavior regulation (Master's thesis). University of Jyväskylä, Jyväskylä, Finland.

Tušak, M. (1997). Razvoj motivacijskega sistema $v$ športu [The development of motivational system in sport] (Doctoral dissertation). University of Ljubljana, Ljubljana, Slovenia.

Tušak, M., \& Tušak M. (1997). Psihologija športa [Sport psychology]. Ljubljana, Slovenia: Science Institute of the Faculty of Arts.

Vilhjalmsson, R., \& Thorlindsson, T. (1992). The integrative and physiological effects of sport participation - A study of adolescents. Sociological Quarterly, 33, 637-647.

Vivi, A., \& Juneman, A. (2015). Predictive analysis of hiphop dancers' motivation for choreographing from choreography components (body-thinking-space-time). Anima Indonesian Psychological Journal, 31, 1-13.

Webster, J., \& Martocchio, J. J. (1992). Microcomputer playfulness: Development of a measure with workplace implications. MIS Quarterly, 16, 201-226.

Webster, J., Trevino, L. K., \& Ryan, L. (1993). The dimensionality and correlates of flow in human-computer interactions. Computers in Human Behavior, 9, 411-426.

Zaletel, P., Tušak, M., \& Zagorc, M. (2006). Plesalec športnik in umetnik [Dancer - An athlete and an artist]. Ljubljana, Slovenia: University of Ljubljana. 